Review

\title{
Ionic Liquid-Based Quartz Crystal Microbalance Sensors for Organic Vapors: A Tutorial Review
}

\author{
Bishnu P. Regmi ${ }^{1, * \mathbb{D}}$, Puspa L. Adhikari ${ }^{2}$ and Beni B. Dangi ${ }^{1}$ \\ 1 Department of Chemistry, Florida Agricultural and Mechanical University, Tallahassee, FL 32307, USA; \\ beni.dangi@famu.edu \\ 2 Department of Marine and Earth Sciences, The Water School, Florida Gulf Coast University, \\ Fort Myers, FL 33965, USA; padhikari@fgcu.edu \\ * Correspondence: bishnu.regmi@famu.edu
}

check for updates

Citation: Regmi, B.P.; Adhikari, P.L.; Dangi, B.B. Ionic Liquid-Based Quartz Crystal Microbalance Sensors for Organic Vapors: A Tutorial Review. Chemosensors 2021, 9, 194 https://doi.org/10.3390/

chemosensors 9080194

Academic Editor: Salih Okur

Received: 30 June 2021

Accepted: 22 July 2021

Published: 27 July 2021

Publisher's Note: MDPI stays neutral with regard to jurisdictional claims in published maps and institutional affiliations.

Copyright: (c) 2021 by the authors. Licensee MDPI, Basel, Switzerland. This article is an open access article distributed under the terms and conditions of the Creative Commons Attribution (CC BY) license (https:// creativecommons.org/licenses/by/ $4.0 /)$.

\begin{abstract}
Organic vapor sensors are used in diverse applications ranging from environmental monitoring to biomedical diagnostics. Among a number of these sensors, quartz crystal microbalance (QCM) sensors prepared by coating ionic liquids (ILs) or their composites are promising devices for the analysis of volatile organic compounds (VOCs) in complex chemical mixtures. Ionic liquids are remarkable materials, which exhibit tunable physico-chemical properties, chemical and thermal stability, multiple interactions with diverse group of molecules, and enormous structural variability. Moreover, ILs exhibit viscoelastic properties, and hence these materials are ideal for creation of QCM virtual sensor arrays. While the scientific literature on IL-coated QCM sensors is rapidly growing, there is still much to learn. This manuscript provides a comprehensive review on the development of IL-coated QCM sensors and multi-sensor arrays as well as their applications for the analysis of VOCs in complex mixtures. Furthermore, IL-coated QCM virtual sensor arrays and their applications are presented. A short overview of some of the QCM designs, future research areas, and recommendations are also discussed. This short review is a necessary first step towards standardization and further development of QCM for the analysis of VOCs.
\end{abstract}

Keywords: volatile organic compounds; QCM; piezoelectric; ionic liquids; composites; multi-sensor arrays; virtual sensor arrays

\section{Introduction}

Volatile organic compounds (VOCs) are organic chemical compounds which evaporate under normal conditions of temperature and pressure [1]. VOCs are also defined as the organic compounds with an initial boiling point of $250{ }^{\circ} \mathrm{C}$ or less at a standard atmospheric pressure of $101.3 \mathrm{kPa}$ [1]. VOCs are found both in indoor and outdoor environments. They are emitted in the atmosphere from a wide variety of natural and anthropogenic sources; the natural sources include plants, animals, natural vegetation fires, and volcanoes, while the anthropogenic sources include transportation, industrial activities, biomass burning, solvent use, and agricultural activities. Each VOC has its own toxicity and potential of causing adverse health effects. While some VOCs have no known health effects, others are highly toxic and carcinogenic; for example, benzene and 1,3-butadiene are known human carcinogens, acrylonitrile is a probable human carcinogen, and dichloromethane is carcinogenic to animals $[2,3]$.

Different types of VOC analyzers are used in monitoring of air quality [4], detection of food adulteration [5], detection of fuel adulteration [6], detection of explosives [7], discrimination of microbial species [8], and diagnosis of plants [9] and human diseases [10,11] The gold standard technique for VOC detection is gas chromatography coupled with mass spectrometry (GC-MS). However, GC-MS is generally bulky, expensive, requires high maintenance cost and efforts, and requires a skilled technician for operation and 
maintenance. An alternative tool that has attracted considerable interest recently is an electronic nose (eNose) device, which comprises an array of cross-reactive sensors (multisensor arrays) and an appropriate pattern-recognition system that is able to recognize simple or complex odors [12]. Commonly used pattern recognition systems include principal component analysis (PCA), factorial analysis (FA), linear discriminant analysis (LDA), artificial neural network (ANN), partial least square regression (PLS), and support vector machine (SVM) [13,14]. Quartz crystal microbalance (QCM), which works based on gravimetric detection principle, is an excellent device that is amenable for the creation of low cost and portable eNose systems [15]. A QCM sensor comprises a piezoelectric AT-cut quartz crystal that is sandwiched between two metallic electrodes, and the front electrode is coated with a suitable chemically selective material known as a sensing material. Sensing materials are essential components of a QCM sensor since the sensitivity and selectivity of a sensor is dependent on the sensing materials used. A wide range of materials, including polymers [16,17], molecularly imprinted polymers [18,19], metal-organic frameworks [20,21], carbon nanotubes [22,23], dendrimers [24,25], porphyrins/metalloporphyrins [26-28], phthalocyanines/metallophthalocyanines [29-31], calixarenes [32,33], nanocomposites [34-36], and ionic liquids (ILs) [37,38], among others, have been investigated as sensing materials for a QCM sensor. Among all of these, ILs are a remarkable class of materials, which have received widespread attention as QCM coating materials in the last two decades. ILs are nonvolatile, chemically and thermally stable, and exhibit synthetic flexibility and multitude of interactions with analyte molecules, and these unique characteristics of ILs make them ideal sensing materials.

Here, we provide a comprehensive review of the rapidly growing scientific literature on the development of IL-coated QCM sensors/sensor arrays and their applications for the analysis of complex mixtures of VOCs. Interested readers are referred to recently published reviews that cover other QCM sensing materials [39-43]. This manuscript summarizes: (i) The working principle of QCM and QCM-D (quartz crystal microbalance with dissipation monitoring); (ii) ILs and their characteristic properties that make them suitable sensing materials for QCM; (iii) recent advances in IL-coated QCM sensors and multi-sensor arrays; and (iv) recent advances in IL-coated virtual sensor arrays and their applications. Finally, future prospects of IL-based QCM/QCM-D sensors in the field of organic vapor sensing and recommendations for the improvement of the QCM sensors are also discussed. This short review is a necessary first step towards standardization and further development of QCM for the analysis of volatile organic compounds (VOCs).

\section{Operating Principle of a QCM Sensor}

A QCM comprises a thin disc of piezoelectric AT-cut quartz crystal that is sandwiched between two metallic electrodes (usually gold electrodes). The application of an alternating electric field across the two metallic electrodes induces the crystal to vibrate in the thickness shear modes with resonant frequencies in the megahertz region (MHz). Figure 1 shows the top, bottom, and side views of a quartz crystal resonator. The direction of the particle displacement is parallel to the surface of the crystal, while the direction of wave propagation is perpendicular to the crystal surface. The shear wave is characterized by frequency and amplitude.

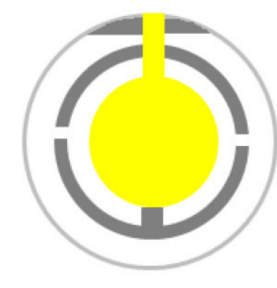

(a)

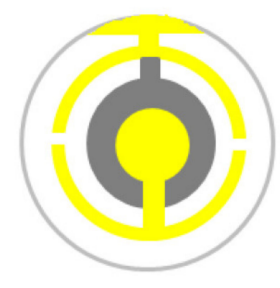

(b)

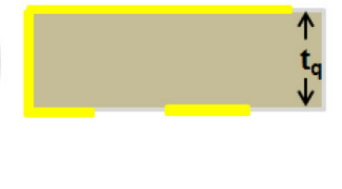

(c)

Figure 1. A typical quartz crystal resonator used in a QCM sensor (a) the top view of the quartz crystal, which shows a circular gold electrode in the center, (b) the bottom view of the crystal, and (c) the side 
view of the crystal. Figure is reproduced from [44]. The electrode on the bottom side is also circular but smaller than the top electrode. The electrical contact to both the electrodes is provided from the bottom side. The resonant frequency depends on the thickness $(t q)$ of the crystal.

The frequency of the acoustic wave under resonance condition is inversely proportional to the thickness of the crystal [45]. The thickness of the crystal $\left(t_{q}\right)$ is related to the velocity of acoustic wave in quartz $\left(V_{q}\right)$ fundamental resonant frequency $(f)$ by the following equation [46].

$$
t_{q}=\frac{V_{q}}{2 f}
$$

The thickness of the quartz crystal is $334 \mu \mathrm{m}$ for a $5 \mathrm{MHz}$ crystal, $167 \mu \mathrm{m}$ for a $10 \mathrm{MHz}$ crystal, and $11 \mu \mathrm{m}$ for a $150 \mathrm{MHz}$ crystal. While thinner crystals provide higher sensitivity, they are fragile and hence difficult to handle [47].

Upon addition of a uniform layer of a foreign material to the surface of the crystal, the frequency of the acoustic wave decreases due to an increase in the thickness. The change in resonant frequency due to the deposition of a film is given by Sauerbrey equation developed by G. Sauerbrey in 1959 [48].

$$
\Delta f=-\frac{n}{C} \Delta m
$$

where $\Delta f$ is the change in resonant frequency, $n$ is the harmonic number that is an odd integer, $\Delta m$ is the mass per unit area of the film (in air or vacuum), and $C$ is the Sauerbrey mass sensitivity constant which is dependent on the fundamental resonant frequency and the properties of the quartz. The value of $C$ is $17.7 \mathrm{ng} \mathrm{cm}{ }^{-2} \mathrm{~Hz}^{-1}$ for a $5 \mathrm{MHz}$ AT-cut quartz crystal; this means that $17.7 \mathrm{ng} \mathrm{cm}^{-2}$ mass on the surface of a $5 \mathrm{MHz}$ AT-cut quartz crystal produces a frequency change of $1 \mathrm{~Hz}$. The smaller the value of $C$, the greater is the mass sensitivity. Thinner crystals provide better mass sensitivity as they have higher fundamental resonant frequency. However, thinner crystals are more fragile and difficult to handle; in addition, an increase in the fundamental resonant frequency of the crystal also leads to an increase in measurement noise. Thus, a compromise must be made while choosing the crystals. Typical operating range of commercially available crystals are 5-10 MHz [49]. When a QCM sensor is exposed to analytes, the absorption/adsorption of analytes leads to a change in mass of the film, thereby decreasing the resonant frequency, which can be correlated to analyte's concentration in a sample. It should be remembered that Sauerbrey equation is valid for thin and rigid films.

Another case that is commonly observed is the one in which one face of the quartz crystal resonator is in contact with a Newtonian liquid. The change in the resonant frequency in this case is given by the Kanazawa-Gordon equation (developed by Kanazawa and Gordon in 1985) [50].

$$
\Delta f=-f^{3 / 2}\left(\frac{\eta_{L} \rho_{L}}{\pi \mu_{Q} \rho_{Q}}\right)^{\frac{1}{2}}
$$

where, $f$ is the fundamental resonant frequency of the free (dry) crystal, $\eta_{L}$ is the absolute viscosity of the liquid, $\rho_{L}$ is the density of the liquid, $\mu_{Q}$ is the elastic modulus of the quartz, and $\rho_{Q}$ is the density of the quartz.

Ionic liquids are viscoelastic, as they show both elastic and viscous properties. In the case of viscoelastic films, in addition to resonant frequency, the quality factor ( $Q$ factor) can provide additional information. The $Q$ factor is defined as the ratio of stored energy over dissipated energy per oscillation cycle. The commonly used parameter is dissipation factor $(D)$, which is reciprocal of the $Q$ factor [51]. Some QCMs use motional resistance $\left(R_{m}\right)$ instead of dissipation factor, and $Q$ and $R_{m}$ are related by Equation (4) [52].

$$
D=\frac{1}{Q}=\frac{E_{\text {dissipated }}}{2 \pi E_{\text {stored }}}
$$




$$
D=\frac{R_{m}}{2 \pi f L_{m}}
$$

where, $R_{m}$ represents the resistance and $L_{m}$ represents the inductance of the ButterworthVan-Dyke (BVD) equivalent circuit model for quartz crystal resonator.

For the rigid films, the change in dissipation factor $(\Delta D)$ or motional resistance $(\Delta R)$ is zero [53,54]. However, in the case of viscoelastic films, both $\Delta f$ and $\Delta D$ (or $\Delta R$ ) depend on the thickness as well as the viscoelastic properties of the films. For Maxwell viscoelastic fluids, $\Delta f$ and $\Delta D$ (which can be simultaneously measured) are related to other parameters as [54]:

$$
\Delta f \approx-\frac{t_{f} \rho_{f \omega}}{2 \pi t_{Q} \rho_{Q}}\left(1+\frac{t_{f}^{2} \rho_{f} \omega^{2}}{3 \mu_{f}}\right)
$$

where, $t_{f}$ is the thickness of the film, $\rho_{f}$ is the density of the film, $\omega$ is the angular frequency of oscillation, $t_{Q}$ is the thickness of the quartz wafer, $\rho_{Q}$ is the density of the quartz, and $\mu_{f}$ is elastic shear modulus of the film.

$$
\Delta D \approx \frac{2 t_{f}^{3} \rho_{f}^{2} \omega}{3 t_{Q} \rho_{Q} \eta}
$$

where, $\eta$ is the shear viscosity coefficient of the film, and other parameters are the same as those in Equation (6). Equations (6) and (7) are particularly useful in explaining the changes in resonant frequencies and dissipation factor in ionic liquid-based QCM sensors.

\section{Ionic Liquids}

Ionic liquids (ILs) have emerged as an attractive class of sensing materials for a QCM device. They are organic salts, which melt at or below $100{ }^{\circ} \mathrm{C}$. The ILs that exist as liquids at room temperature are commonly referred to as room temperature ionic liquids (RTILs), while those which exist as solids are sometimes referred to as frozen ionic liquids [55]. These materials typically comprise low symmetry organic cation that is weakly bonded by electrostatic forces to an inorganic/organic anion [56]. ILs have low vapor pressure, high thermal stability, high chemical stability, and moreover, they are nonflammable and their selectivity can be easily tuned by altering the cation and/or anion $[57,58]$. The thermal stability of ILs depends on their structure, and it has been reported that anion is a major determinant of thermal stability [58]. A large number of ILs can be prepared by combining cations and anions; thus, an estimated one million simple ILs can be synthesized [59,60]. ILs show a multitude of interactions with organic compounds, which include dispersion, dipole type, hydrogen bond, and electron lone pair interactions [61]. The attraction between an IL and organic molecule is dependent on the relative contributions of these interactions, which depend on the structure of ILs; and hence, the chemical selectivity of ILs to organic vapors can be tuned by modifying the structures of ILs. For example, it has been demonstrated that 1-butyl-3-methylimidazolium chloride $(\mathrm{BMImCl})$ preferentially interacts with alcohols as compared to other classes of organic compounds [62]. Oxygen in alcohol has partial negative charge and can form hydrogen bonding with positively charged hydrogen atom (attached to nitrogen) of $\mathrm{BMImCl}$; in addition, the positively charged hydrogen atom of alcohol can interact with negatively charged chloride ion [62]. The hydrogen atoms, which are bonded to carbon, for example, do not interact strongly with the chloride ion. Because of their unique properties, ILs have been widely employed as stationary phases in gas chromatography columns, and IL-coated columns are being commercially produced since 2008 [63-67]. In addition, ILs have been used in a wide range of applications, such as in electrochemical sensing [68], MALD-MS [69], catalysis [70], liquid-liquid extraction [71], and others [72]. There is a rapid diffusion of VOCs in ILs and the absorptions is reversible. ILs, almost exclusively RTILs, have been widely used for coating on a QCM device. Figure 2 shows chemical structures of some typical cations and anions commonly employed in the synthesis of ILs. 
<smiles>[R][P+]([R])([R])[R]</smiles><smiles>[R][N+]([R])([R3])[R]</smiles><smiles>[R][Sb]([R])[R]</smiles><smiles></smiles><smiles>[R1]n1cc[n+]([R1])c1</smiles><smiles>[R]c1n([R3])cc[n+]1[R]</smiles><smiles>[R][N+]1([R])CCCC1</smiles><smiles>[R][N+]1([R])CCCCC1</smiles><smiles>F[As](F)(F)(F)(F)F</smiles><smiles>F[Sb-](F)(F)(F)F</smiles><smiles>O=S(=O)(NS(=O)(=O)C(F)(F)F)C(F)(F)F</smiles><smiles>O=S(=O)([O-])C(F)(F)F</smiles><smiles>N#CNC#N</smiles><smiles>COS(=O)(=O)[O-]</smiles>

$$
\mathrm{Cl}^{\ominus}, \mathrm{Br}^{\ominus}, \mathrm{I}^{\ominus}, \mathrm{NO}_{3}^{\ominus}
$$

Figure 2. Some typical cations and anions used for the synthesis of ILs. Figure is reproduced from [44].

\section{Advancements in Ionic Liquid-Based Materials for QCM Sensors}

Different compounds and/or mixtures analyzed by IL-based QCM sensors and sensor arrays are summarized in Table A1. Below we discuss some details of these studies.

\subsection{Ionic Liquid-Based QCM Sensors and Multi-Sensor Arrays}

The first use of ILs to develop QCM sensors was reported by Liang et al. [37] in 2002. The authors employed several ILs comprising imidazolium-based cations paired with bis (trifluoromethylsulfonyl) imide and tetrafluoroborate anions. The ILs were spin-coated on the surface of a $6 \mathrm{MHz}$ AT-cut quartz crystal (12.5 mm diameter). Liang et al. [37] tested 11 different organic vapors, and the sensors displayed a rapid response with a response time of approximately $2 \mathrm{~s}$; the vapor sorption was fully reversible, as shown in Figure 3 . It is evident from this figure that on exposure to acetone vapors (which is also true for other vapors), the resonant frequency of the QCM sensor increases. The Sauerbrey Equation, however, predicts a decrease in resonant frequency during the sorption of vapors by the IL films owing to an increase in the mass of the film. The increase in resonant frequency during vapor sorption was explained by using Kanazawa-Gordon equation. Upon vapor sorption, the viscosity and density of the film decrease, resulting in an increase in resonant frequency. The decrease in viscosity of ILs is much more pronounced than a decrease in their density. A plot of frequency change of the sensor as a function of concentration of organic vapors was found to vary linearly. 


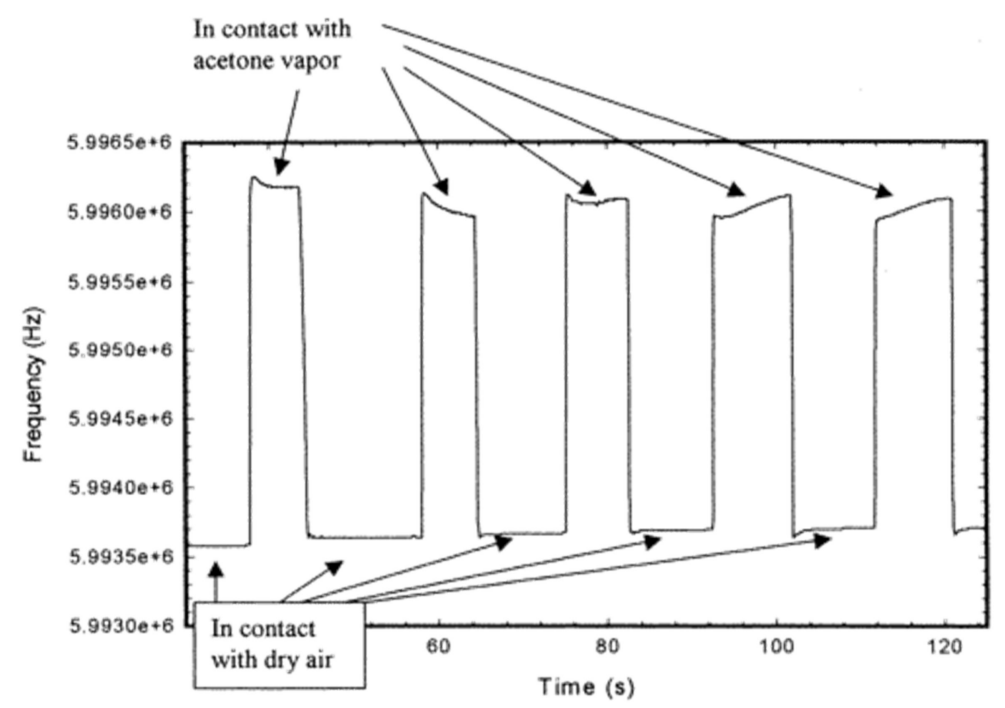

Figure 3. The response of an IL-coated QCM sensor on alternate flushing with saturated acetone vapors and dry air. Figure is reproduced from [37].

The IL films used by Liang et al. [37] were relatively thick, and the long-term stability of these films were not reported. Some potential problems of IL films include dewetting and flow of ILs, thereby compromising the integrity of the films. Goubaidoulline et al. [73] presented a concept of immobilizing an IL inside the pores of a nanoporous alumina layer, which was grown on the front electrode of the quartz crystal through anodization process. ILs were then immobilized inside these nanopores through spin coating using a $10 \% \mathrm{IL}$ solution in acetonitrile. The resonant frequency was found to decrease during vapor absorption - as predicted by the Sauerbrey equation -While the bandwidth of the resonance remained unchanged indicating the absence of viscoelastic effects. The response was found to be linear with the activity of vapors. Goubaidoulline et al. [73] also determined Henry's constants for six organic solvents (acetonitrile, cyclohexane, isooctane, methanol, tetrahydrofuran, and toluene). While the authors were successful in eliminating problems related to liquid's softness, dewetting, and liquid flow, the desorption rate of vapors was found to be slow due to the confinement of ILs inside alumina nanopores.

Subsequent studies on IL-coated QCM sensors have been focused on increasing the sensitivity of the sensors as well as developing multi-sensor arrays for the analysis of complex samples. Toward this end, Seyama et al. [74] prepared plasma-polymerized films by radio frequency sputtering of D-phenylalanine on the surface of quartz crystal resonator. The authors incorporated 1-ethyl-3-methylimidazolium tetrafluoroborate (EMI-TFB) to this plasma-polymerized film by dropping a solution of EMI-TFB on the surface of the films. They created a sensor array containing four sensor elements; one sensor element contained only D-phenylalanine film, while other three elements contained different amounts of EMI-TFB. This sensor array was used for the discrimination of four normal alcohols, including methanol, ethanol, n-propanol, and n-butanol with concentrations ranging from 16 to $84 \mathrm{ppmv}$. The PCA scores plot exhibited separate areas for these alcohols, as displayed in Figure 4.

Jin et al. [75] developed an IL-coated QCM sensor array using seven ILs for the detection of organic vapors at ambient and high temperatures (e.g., $120^{\circ} \mathrm{C}$ ). The authors used two imidazolium ILs, four phosphonium ILs, and one ammonium IL to construct the sensor array. The thickness of the IL films was kept less than $200 \mathrm{~nm}$; and, a decrease in resonant frequency was observed on exposure to organic vapors. Four analytes, including ethanol, dichloromethane, benzene, and heptane were selected as analytes. Figure 5 shows LDA canonical scores plot of four organic vapors of different concentrations; seven replicate measurements were taken for each vapor. A classification accuracy of $96 \%$ was achieved for unknown concentration (1 misclassified out of 28 measurements), while $100 \%$ accuracy was achieved for known concentrations. The response of IL-coated sensors was found 
to decrease exponentially with temperature, and this can be attributed to a decrease in absorption with an increase in temperature [75]. Rehman et al. [76] developed a sensor array comprising eight sensor elements each coated with an IL. The sensor array was used for the discrimination of a closely related explosive compounds; and the authors were able to discriminate nitromethane, 1-ethyl-2-nitrobenzene, and a mixture of these two compounds with a reasonably high accuracy using LDA algorithm. Jin et al. [77] prepared a multichannel monolithic quartz crystal microbalance (MQCM) which was fabricated by using four pairs of electrodes on a single $10 \mathrm{MHz}$ quartz crystal. Each of the four QCM in the MQCM was found to behave like an independent sensor. To construct a sensor array, two of the four electrodes were coated with ILs, the third electrode one was coated with a conductive polymer poly(vinylferrocene), and the fourth electrode was left bare. The MQCM exhibited 100\% accuracy for the classification of ethanol, hexane, and dichloromethane using LDA.

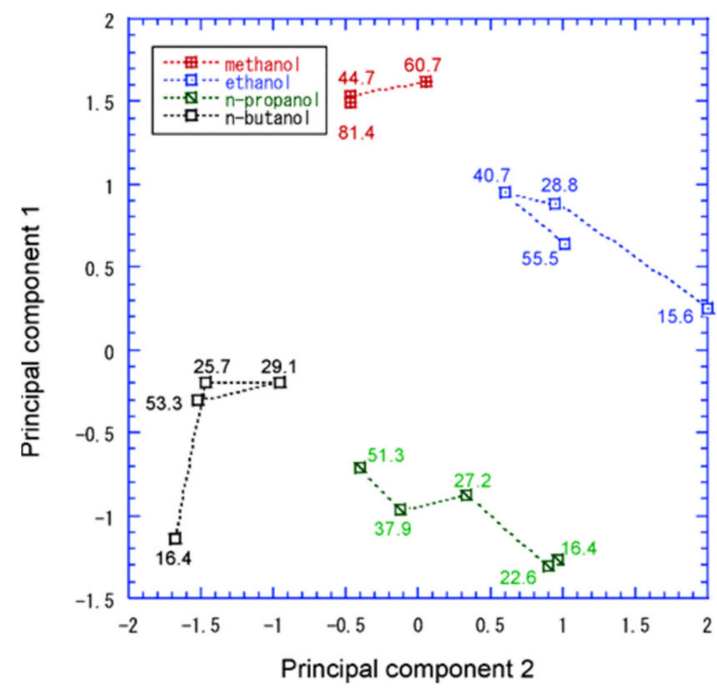

Figure 4. Principal component analysis (PCA) scores plot obtained with sensor array responses resulting from exposure to different vapors. Numbers indicate the concentration of each alcohol in ppmv unit. Figure is reproduced from [74].

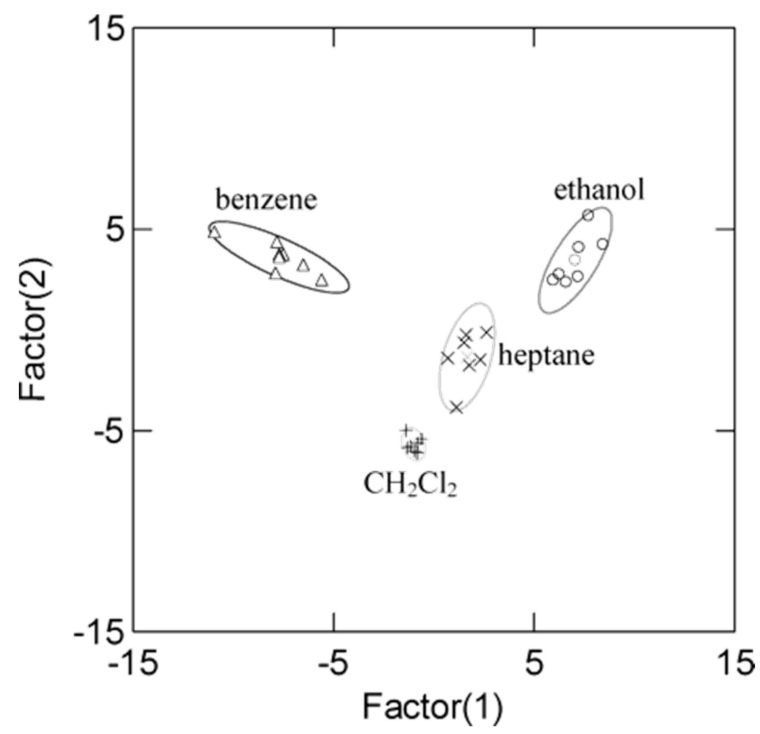

Figure 5. Linear discriminant analysis (LDA) canonical scores plot of four organic vapors with different concentrations tested with an IL-coated QCM sensor array. Seven replicate measurements were taken for each vapor. Figure is reproduced from [75]. 
$\mathrm{Xu}$ et al. [78] investigated six ILs as QCM sensing materials to detect a number of organic vapors, including acetone, benzene, dichloromethane, ethanol, hexane, and toluene. The authors found that chloride- and bromide-containing imidazolium ILs were 2.6-30 times more selective to ethanol as compared to other vapors. These halidecontaining ILs were further used to detect methanol and propanol; and, as low as $6.0 \mathrm{ppmv}$ of propanol and $10 \mathrm{ppmv}$ ethanol have been detected. The high sensitivity of imidazoliumbased halides was attributed to hydrogen bonding interactions between the ILs and alcohols $[62,78]$. The response of these sensors was, however, found to decrease with water vapors; and the calibration curves were found to remain linear. In separate studies, $\mathrm{Xu}$ et al. [79] further developed a QCM sensor arrays, where three QCM sensor elements were prepared by coating imidazolium-based ionic liquids and one QCM sensor element by coating silicone oil. The sensor array was used for the discrimination of acetone, dichloromethane, ethanol, and toluene with $100 \%$ identification accuracy using artificial neural network (ANN) algorithm. After the identification of an analyte, the sensor array was also employed for quantitative analysis of these four analytes, and the prediction errors were found to be less than $8 \%$.

There have been attempts to use an IL-coated QCM sensor array for the analysis of food flavors. In this regard, Toniolo et al. [80] developed a QCM sensor by coating seven commercially available ionic liquids. The sensor array was first applied to classify 31 compounds belonging to different chemical classes including hydrocarbons, terpenes, alcohols, aldehydes, esters, phenols, ketones, amines, and acids. These compounds were selected as representative compounds present in a range of food flavors. PCA of the data showed a separate cluster for each chemical class. The sensor array was then applied for the analysis of headspace vapors of two different botanical varieties of cinnamon including Cinnamon zeylanicum and Cinnamon cassia. Three batches of cinnamon sticks with two replicate measurements were analyzed. PCA showed two separate clusters for these two botanical species, as shown in Figure 6. These studies demonstrated an IL-coated QCM sensor array provides high enough sensitivity and selectivity for the differentiation of odors released from quite similar flavor sources.

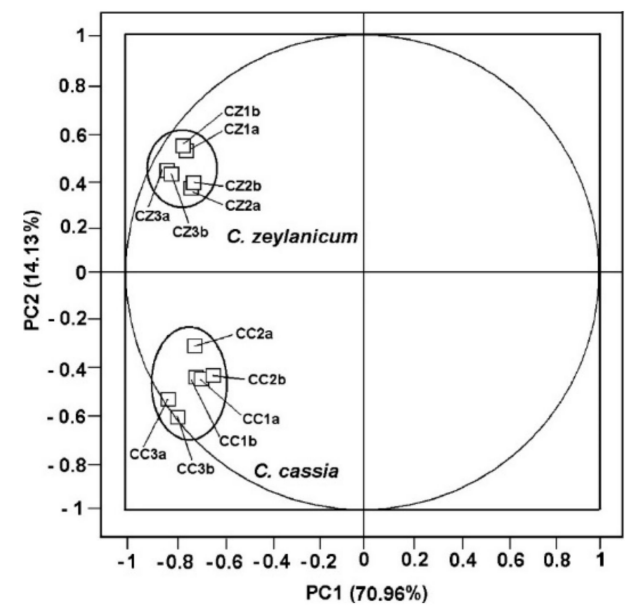

Figure 6. Loading plot obtained by PCA for headspace vapors from ground samples of C. zeylanicum (CZ) and C. cassia (CC). Numbers are used to indicate different cinnamon batches, while letters $(a)$ and $(b)$ are used to indicate replicate measurements on different portions of the same cinnamon batch. Figure is reproduced from [80].

Ionic liquids are amenable to form composite materials [81-83]. Considering this property of ILs, several efforts have been made to enhance the sensitivity and selectivity of a QCM sensor by using ILs in conjunction with other materials [84-86]. For example, Jin et al. [84] attempted to increase the sensitivity of a QCM sensor by using a polymer scaffold, because just simply changing the thickness of the IL film does not increase the 
sensitivity. The authors created a scaffold on the surface of quartz crystal by electrochemically depositing partially oxidized polyaniline (PAn) (emeraldine salt) film, which was then used as a template to immobilize an IL, butylmethylimidazolium camphorsulfonate (BMICS). The IL was deposited on the surface of PAn film using solutions of the IL in ethanol. The sensor was employed to detect methane, and a detection limit of $115 \mathrm{ppm}$ was achieved. As shown in Figure 7, there is a significant enhancement in sensitivity of the sensor prepared by depositing BMICS on the PAn film. The interactions between IL and charged PAn could have possibly increased the wettability of IL films. Hou et al. [85] have recently reported immobilization of ILs on polyvinyl ferrocene films with varied oxidation states to enhance sensitivity and selectivity towards several VOCs. Ji et al. [86] presented a concept of using composites of graphene/ILs for highly selective sensing of aromatic vapors. The film graphene/ILs were deposited on the QCR surface by reduction of graphene oxide in the presence of ILs followed by layer-by-layer assembly.

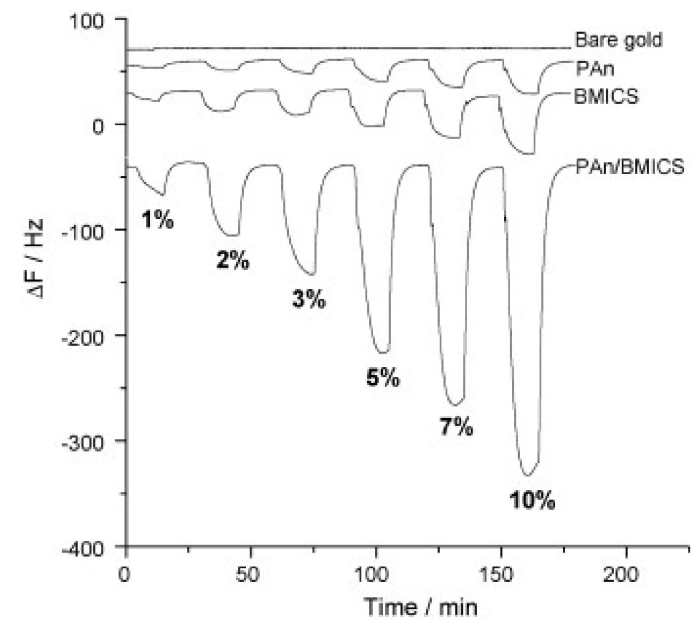

Figure 7. Frequency changes upon methane absorption and desorption on bare gold, PAn, BMICS, and emeraldine salt PAn/BMICS-coated QCM devices at room temperature. Figure is reproduced from [84].

\subsection{Reaction-Based Sensing Ionic Liquids for QCM Sensors}

The ionic liquids that we discussed above show reversible response, meaning that the analytes can be easily desorbed by blowing an inert gas [37]. There are several attempts to develop QCM sensors using specific chemical reactions of ILs with analytes, which can significantly increase the sensitivity and selectivity for several organic vapors; and, this type of ILs has been referred to as 'sensing ionic liquids' (SILs) [87-93]. Tseng and Chu [87] synthesized three SILs and used them for highly sensitive and selective detection of aldehyde, ketones, and amines. For example, one of the SILs contains an amine group in the side chain, and this readily reacts with aldehyde and ketone gases to produce covalent imine adducts; and, by using this SIL the authors estimated the sensitivity of detection to be $4.5 \mathrm{ppb}$ for butyraldehyde. In another set of studies, the authors reported highly sensitive and selective detection of organic azide gases through the use of [3+2] cycloaddition reaction with an SIL at room temperature [88]. The sensitivity of detection was found to be $5 \mathrm{ppb}$ for benzyl azide and $35 \mathrm{ppb}$ for butyl azide [88]. Similarly, Liu et al. [89] synthesized SILs for QCM-based detection of cyclic and acyclic ketones, and the sensitivity of detection was $0.6 \mathrm{ppb}$ for cyclohexanone and $1.1 \mathrm{ppb}$ for acetone. The research in the synthesis of SILs and their use to develop QCM sensors continued to grow. Li et al. [91] reported detection of aldehydes and ketones gases by using silver ILs. Hsu et al. [92] reported the detection of alkenes gas through the use of Diels-Alder [4+2] cycloaddition reaction of alkenes with so-called functional ionic liquids, and the sensitivity of detection was reported to be $1.5 \mathrm{ppb}$ for cyclopentadiene. $\mathrm{Li}$ and $\mathrm{Chu}$ [93] reported detection of alcohol and amine gases by utilizing triazine-based ILs and nucleophilic aromatic substitution reactions. These reaction-based IL systems provide high sensitivity, high selectivity, and 
no sensitivity to moisture as compared to the ILs discussed in Section 4.1. However, the binding organic molecules to the ILs is irreversible, and hence the IL film on the QCM surface is required to remove by washing after each measurement and replace with a new film. In addition, reaction-based ILs are not ideal for the development of sensor arrays [94].

\subsection{Ionic Liquid-Based QCM Virtual Sensor Arrays}

The QCM sensors and multi-sensor arrays discussed so far are based on the measurements of only one signal response, i.e., frequency shift, per sensor. Since ILs exhibit viscoelastic behavior, a change in motional resistance $(\Delta R)$ or change in dissipation factor $(\Delta D)$ takes place in addition to $\Delta f$ during vapor absorption. Moreover, $\Delta f$ and $\Delta D$ can be measured at multiple harmonics to obtain many signal responses per sensor. A device containing a single physical sensor that is able to produce multiple signal responses has been named as a virtual sensor array (VSA) or multivariable sesnors [95-98]. These types of sensors have emerged in fundamentally different perspective to minimize several limitations associated with the existing sensors [97]. Recently, there have been significant progress in developing VSAs using IL-coated QCM sensors [98-104]. Regmi et al. [99,100] developed QCM sensors by depositing composite materials made by mixing of an IL and a polymer, such as cellulose acetate and polymethylmethacrylate (PMMA). These materials were co-deposited on the QCM surface by using a solvent precipitation method to obtain thin films comprising isolated microdroplets of varying sizes. As shown in Figure 8, the frequency of the QCM sensor coated with an IL-polymer composite decreased, while the motional resistance of the sensor increased on exposure to organic vapors [99]. An intriguing observation of these studies is the correlation of the molecular weight of a vapor to $\Delta f$-to- $\Delta R(\Delta f / \Delta R)$ ratio [99]. Figure 9a shows a linear relationship between the magnitude of $\Delta f$ and $\Delta R$, and this relationship is found to be concentration independent for relatively low vapor concentrations. Figure $9 \mathrm{~b}$ shows that the magnitude of the ratio $\Delta f / \Delta R$ varies linearly with the molecular weight of vapors. Simultaneous measurements of these two parameters is therefore very useful in determining molecular weight of a compound, thereby facilitating its identification. Measurement of either $\Delta f$ or $\Delta R$ alone is not sufficient to know about the molecular identity as the response depends both on the concentration and the identity of the vapor. Viscoelastic modeling using the data obtained from quartz crystal microbalance with dissipation monitoring (QCM-D) for different harmonics showed that these films can be best described by the Maxwell viscoelastic model [100]. The polymers cellulose acetate and PMMA were found to increase the effective viscosity of the IL materials. It should be noted that if the film remains in the thin-film regime, $\Delta f$ varies as a function of mass. On the other hand, $\Delta R$ (or $\Delta \mathrm{D}$ ) depends on the viscosity of the film. The observation that the molecular $\Delta f / \Delta R$ is directly proportional to molecular weight indicates that $\Delta R$, and hence viscosity of the film, depends on the number of moles of a vapor absorbed irrespective of the vapor identity. This observation is clearly consistent with the studies by Seddon and coworkers [105] who reported that the viscosity of a mixture of IL and organic solvent depends primarily on the mole fraction of the solvent in the mixture rather than the identity of the solvent. These studies provided a new dimension in the analysis of vapors by using a QCM sensor.

Speller et al. [98,101-103] conducted in-depth studies in the development of IL-based QCM VSAs and applied these sensor arrays for the discrimination and classification of challenging real-world mixtures, such as gasoline and essential oil samples. In their initial studies, Speller et al. [98] coated the surface of QCM-D crystal with an IL using an electrospray process. The coating thickness was varied by changing the coating time. This resulted heterogeneous films comprised isolated microdroplets of different sizes. The prepared sensor was tested with 18 different organic vapors of the same or different chemical class, including alcohols, aromatic hydrocarbons, chlorinated hydrocarbons, and nitriles. The $\Delta f$ values obtained at different odd harmonics were then analyzed using PCA and discriminant analysis (DA). The VSA allowed to a classification accuracy of nearly $100 \%$ was obtained using the VSA. The VSA was further employed for the discrimination of petroleum ether and kerosene-two representative similar complex mixtures. 


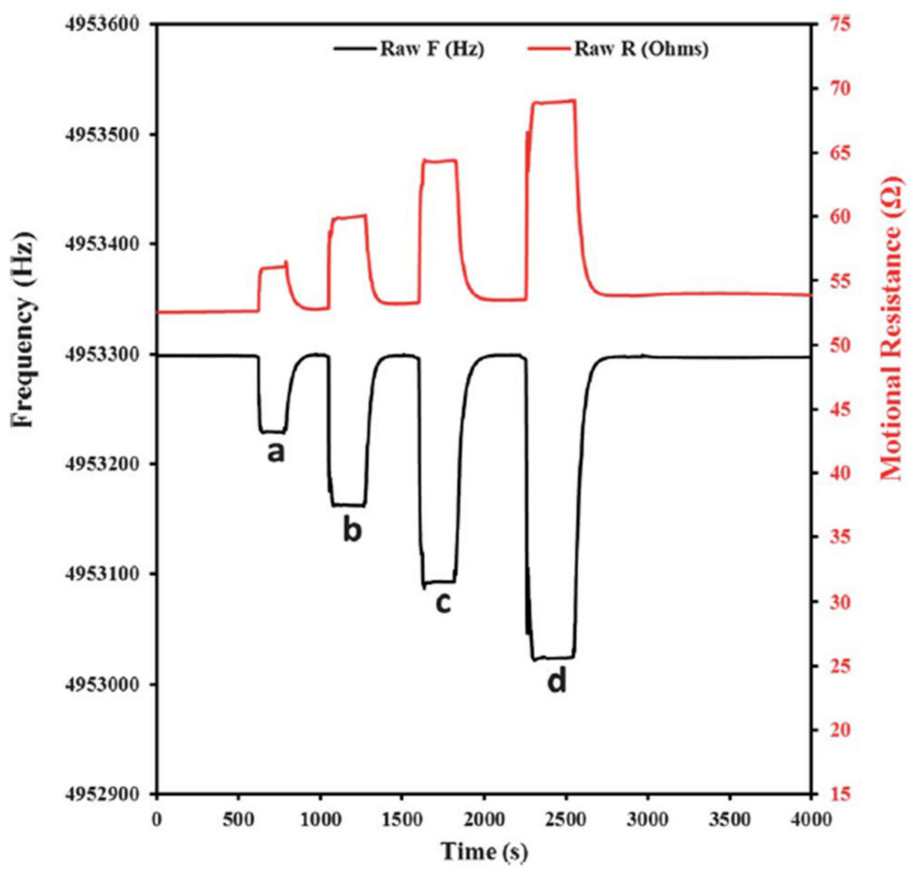

Figure 8. Frequency and resistance changes of a QCM sensor coated with a composite of cellulose acetate and 1-n-butyl-2,3-dimethylimidazolium hexafluorophosphate on exposure to $17.8 \mathrm{mg} \mathrm{L}^{-1}$ (a), $35.6 \mathrm{mg} \mathrm{L}^{-1}$ (b), $53.4 \mathrm{mg} \mathrm{L}^{-1}$ (c), and $71.3 \mathrm{mg} \mathrm{L}^{-1}$ (d) of chloroform vapors. In each case, the liquid sample was injected into the chamber and allowed to vaporize; after equilibrium, the vapor was removed by flushing with UHP argon. Figure is reproduced from [99].

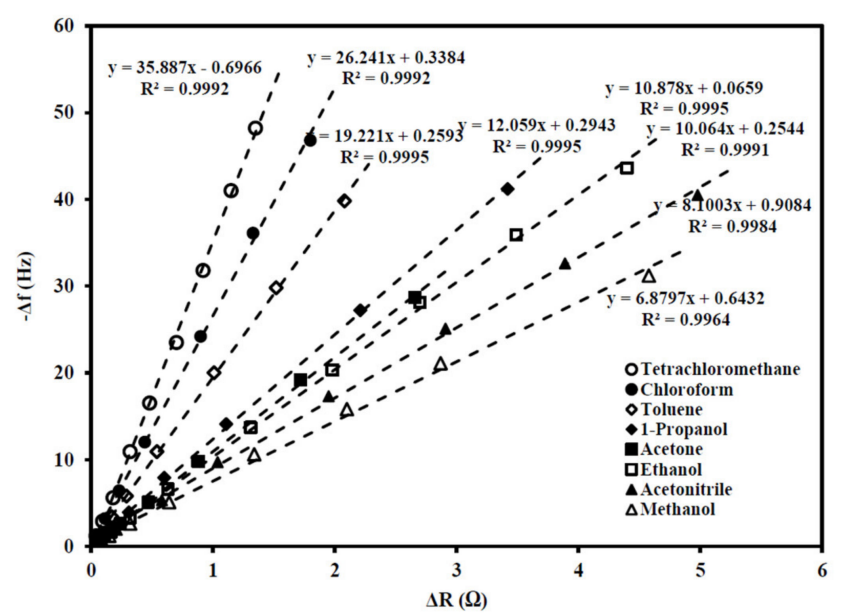

(a)

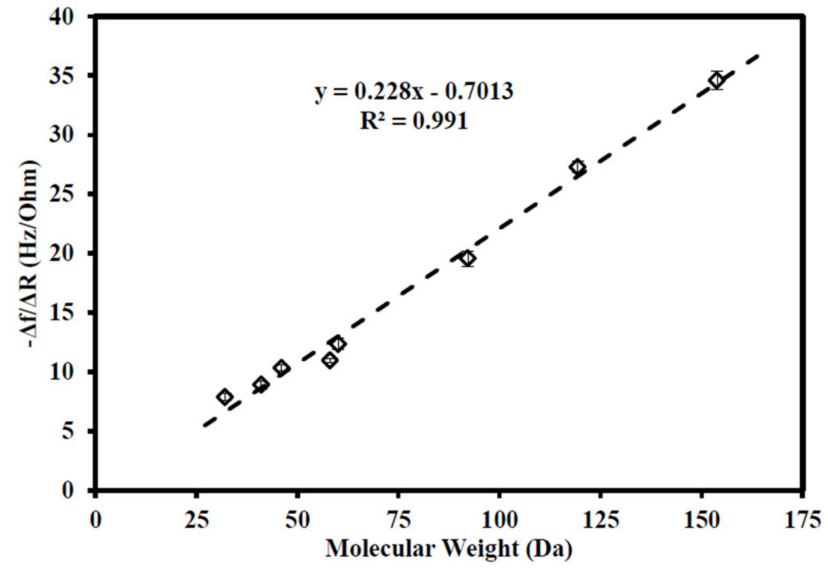

(b)

Figure 9. (a) Plots of $\Delta f$ against $\Delta R$ for a QCM sensor coated with a composite material on exposure to different organic vapors. The vapor concentration ranges: $1.93-77.0 \mathrm{mg} / \mathrm{L}$ for tetrachloromethane, $0.720-28.8 \mathrm{mg} / \mathrm{L}$ for chloroform, 0.209-8.36 mg/L for toluene, $0.194-11.7 \mathrm{mg} / \mathrm{L}$ for 1-propanol, $0.191-11.5 \mathrm{mg} / \mathrm{L}$ for acetone, $0.382-22.9 \mathrm{mg} / \mathrm{L}$ for ethanol, $0.190-4.75 \mathrm{mg} / \mathrm{L}$ for acetonitrile, and $0.574-23.0 \mathrm{mg} / \mathrm{L}$ for methanol. (b) Variation of $\Delta f / \Delta R$ as a function molecular weight of organic vapors. Error bars represent the standard deviations $(n=6-8)$. Figure is reproduced from [99].

Figure 10 shows $\Delta f$ at different harmonics on exposure to petroleum ether and kerosene for two VSAs, one coated with 1-octyl-3-methylimidaolium bromide ([OMIm] [Br]) and the other coated with 1-octyl-3-methylimidaolium thiocyanate ([OMIm][SCN]). Note that the changes in frequency is negative at lower harmonics and positive at higher harmonics. Quadrative discriminant analysis (QDA) was used to classify the petroleum ether 
and kerosene samples. The classification accuracy was found to be $100 \%$. These studies demonstrated that a VSA based on an IL-coated QCM-D is a promising technology for the discrimination and classification of very similar chemical compounds or mixtures.
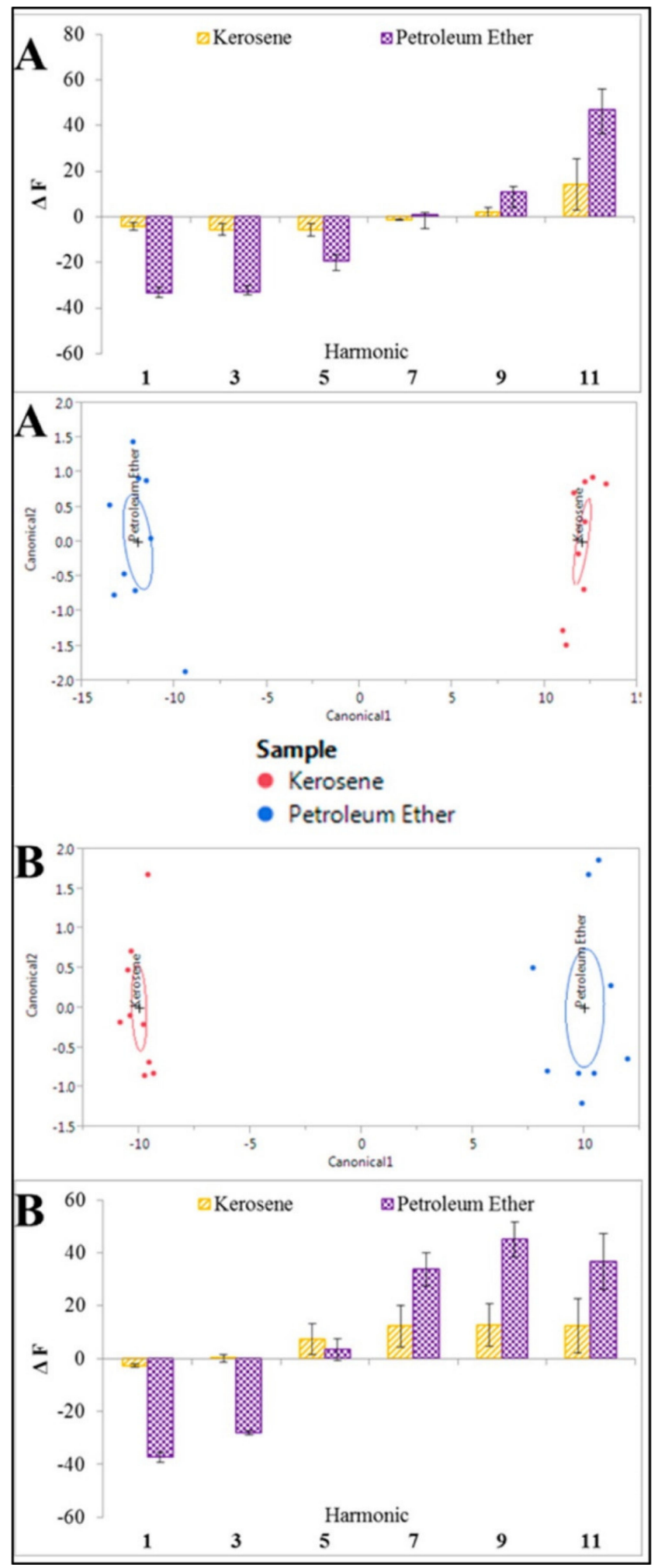

Figure 10. Frequency change at different harmonics and QDA, and canonical plots for petroleum ether and kerosene. (A) VSA coated with [OMIm][Br] and (B) VSA coated with [OMIm][SCN]. Figure is reproduced from [98]. 
Speller et al. [102], in another set of studies, compared the performance of multi-sensor array (MSA), VSA, and MSA and VSA combination (referred to as virtual multisensory array and abbreviated as V-MSA) developed by coating four different ILs. Five essential oil samples, as representative complex mixtures, were used as analytes, and it was demonstrated that the accuracy of classification of these very similar mixtures by V-MSA was superior (accuracy $=100 \%$ ) compared to that of MSA or VSA alone indicating that IL-coated V-MSA is a very promising tool for the analysis of organic vapors in complex mixtures. Speller et al. [103] further developed a V-MSA for accurate discrimination of gasoline grades and adulterated (adulterated with methanol, ethanol, toluene or xylene) gasoline samples. In order to develop the V-MSA, the authors coated four QCM-D surfaces with different ILs. The QCM-D data were analyzed by PCA and LDA. The V-MSA accurately discriminated different gasoline grades as well as gasoline adulterated with several industrial solvents. As low as $1 \%$ adulteration could be accurately discriminated, indicating that the V-MSA could be an exceptional tool for discrimination of highly complex mixtures. Figure 11 shows an LDA canonical plot for the discrimination of gasoline adulterated with different solvents at a $1 \% v / v$ ratio. Vaughan et al. [104] recently developed three VSAs using polydimethylsiloxane (PDMS) incorporated phosphonium ILs. Two of the three VSA discriminated five chlorinated VOCs-dichloromethane, trichloromethane, tetrachloromethane, chloropropane, and chlorobutane-With 100\% accuracy. These studies demonstrated that incorporating polymers in ILs could improve the discrimination accuracy of IL-coated QCM sensor arrays.

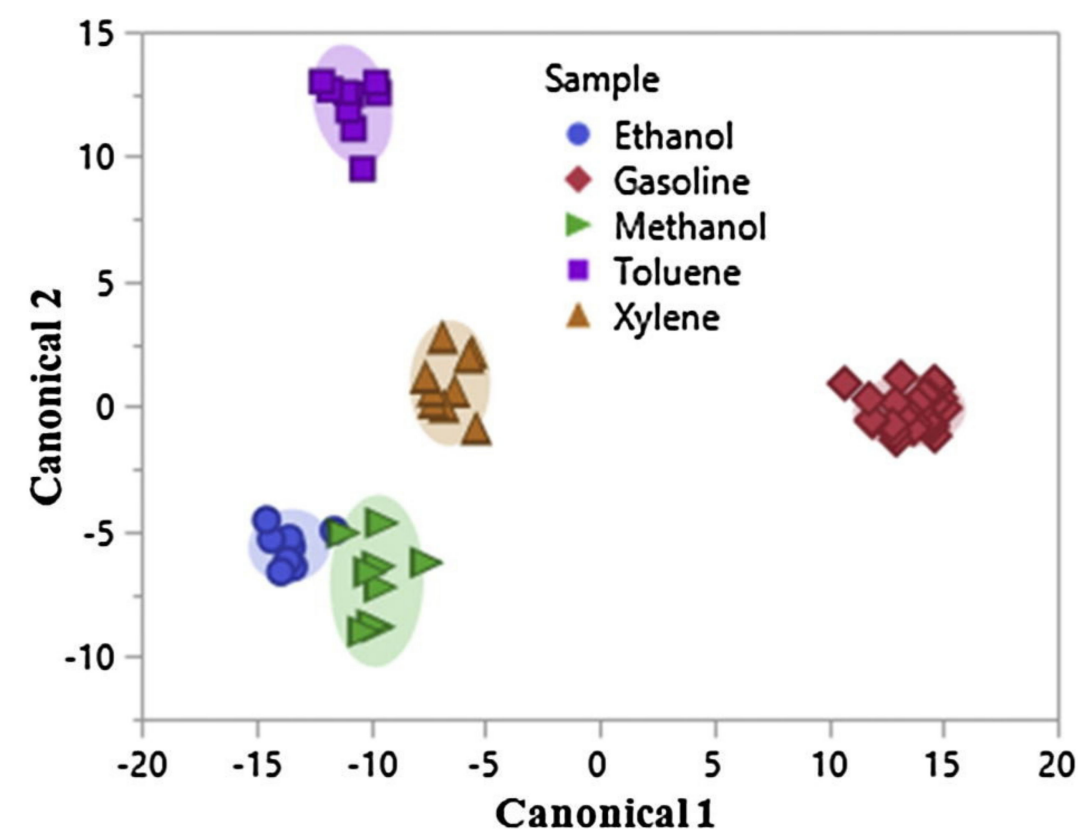

Figure 11. Linear discriminant analysis (LDA) canonical plot showing the discrimination of low-level gasoline adulteration using a V-MSA. Three concentrations of each sample were analyzed in triplicate. Adulterated samples are denoted as Ethanol, Methanol, Toluene, and Xylene. Each sample contains $1 \% v / v$ adulterant; 9 measurements per each adulterant were taken making 36 total measurement for four adulterated sample. The sample denoted as Gasoline contained all measurements ( 9 for each) for Exxon Regular, Exxon Plus, and Exxon Supreme making 27 total measurements. In this plot, there a total of 63 measurements. Figure is reproduced from [103].

Recently, Aleixandre and Nakamoto [106] studied twenty-eight QCM sensors; twentythree of them were coated with ILs, and the remaining five were coated with common GC stationary phase materials. The authors measured both frequency shift and resistant shift of Mason equivalent circuit. A sensor array was then developed using two sensors coated with ILs and two sensors coated with GC stationary phases, and the sensor array 
was used for the discrimination of four organic vapors. It was demonstrated that using both the frequency and resistance data provided better discrimination capability for the sensor array. These studies further demonstrate that obtaining two or more parameters from a single sensor should be a viable alternative for the construction of efficient sensor arrays. The authors obtained the best sensor combination by employing at least one IL film and one conventional film.

\subsection{Ionic Liquid-Like Materials for QCM Sensors and Multi-Sensor Arrays}

Amorphous solid salts (which are solid-state analogues of ILs; also named as Group of Uniform Materials Based on Organic Salts or GUMBOS) and poly(ionic liquid)s have been also investigated as QCM sensing materials for the detection of a number of different organic vapors [107-110]. Regmi et al. [107] synthesized two solid phase amorphous materials, namely copper (II) meso-tetra (4-carboxyphenyl) porphyrin tetra (trihexyltetradecylphosphonium) salt and copper phthalocyanine-3, $4^{\prime}, 4^{\prime \prime}, 4^{\prime \prime \prime}$-tetrasulfonic acid tetra (trihexyltetradecylphosphonium) salt. The QCM sensors developed by coating these two salts were used for sensing of eleven organic vapors. The sensor exhibited very fast response and recovery times to all these analytes, and this response times were similar to what is found in liquid phase ILs. Up to 320-fold improvement in sensitivity (for porphyrin-based GUMBOS) was observed as compared to the previous reports using metalloporphyrins as coating materials, thereby indicating the potential of these materials for a significant enhancement in sensitivity [107,111]. Recently, Vaughan et al. [108] prepared four compounds by pairing copper (II) phthalocyaninetetrasulfonate anions with tetrabutylammonium, tetrabutylphosphonium, 3-(dodecyldimethyl-ammonio)propanesulfonate, and tributyl- $n$-octylphosphonium cations. A QCM sensor array was created and used for the discrimination of ten analytes belonging to four different classes. The accuracy for the classification of these ten analytes into four classes was found to be $98.6 \%$. There a few studies on the use of poly(ionic liquid)s as QCM coating materials for detection of organic vapors. Zhang et al. [109] synthesized imidazolium-based poly(ionic liquid)s and used them as QCM coating materials for detection of VOCs, and a theoretical detection limit of $3.1 \mathrm{ppb}$ is reported for volatile organic acids. The recovery time was found to be less than $40 \mathrm{~s}$. Sipka et al. [110] have recently reported the use of poly(ionic liquid)s as QCM coating materials for the detection of a number of gases including organic vapors.

\section{Conclusions and Future Perspectives}

This article provides an overview on the current state of research in the use of ILs as QCM sensing materials for the detection and classification of complex chemical mixtures comprising VOCs. IL-coated QCM sensors have undergone a significant transformation since they were first introduced by Liang et al. in 2002. Due to a broad diversity of the constituent ions, ILs exhibit remarkable flexibility in tuning their chemical selectivity. There is continuing interest in the development of sensitive and selective QCM sensors using ILs toward the analysis of complex chemical mixtures. Detection limits in lower ppb range have been attained by using IL-coated QCM sensors. Moreover, gasoline samples containing as low as $1 \%$ adulterant have been discriminated. However, the reproducibility and long-term stability of these sensors have not been fully evaluated. Note that the response of a QCM sensor was found to decrease with an increase in humidity and temperature; a strict control of these conditions should be maintained during measurements.

While IL-coated QCM sensors and sensor arrays have potential to analyze much wider range of complex mixtures, a limited number of mixtures have been evaluated under laboratory conditions. In future research works, it would be beneficial to develop more effective MSAs, VSAs, and V-MSAs for fingerprinting of very similar chemical mixtures over a broader range of analytes. Designing more efficient sensor arrays by employing new ILs and optimizing number of sensor elements and optimal sensor combinations by performing in-depth statistical analysis using various statistical algorithms would expand the application of these sensors. In addition, the use of solid-phase amorphous 
organic salts, poly(ionic liquid)s, and diverse IL-based composite materials could be further investigated to improve sensitivity and selectivity for the analysis complex VOC mixtures. Computational chemistry can be used as a tool to estimate the interaction energies between different ILs and different classes of VOCs. This approach will be beneficial for preliminary screening of selective and sensitive sensing materials for eventual development of efficient sensor arrays for the analysis of complex mixtures. An important area of future research is the detection of VOCs emitted from the human body, and these VOCs offer unique insights into the metabolic condition of an individual. The development and use of IL-based QCM for such applications would be a significant step in biomedical analysis. In addition, development of IL-coated QCM chiral sensors by employing chiral ILs as chiral receptors holds great potential as chiral sensing is of fundamental importance in many areas.

Funding: This research received no external funding. The article processing charged was funded by the College of Science and Technology, Florida A and M University.

Conflicts of Interest: Bishnu Regmi holds a patent on detection and molecular weight determination of organic vapors using a QCM sensor coated with GUMBOS-polymer composite materials. Puspa Adhikari and Beni Dangi declare no competing financial interests.

\section{Appendix A}

Table A1. Summary of analytes detected by IL-based QCM Sensors.

\begin{tabular}{|c|c|c|}
\hline VOCs or Complex Mixtures Analyzed & QCM Sensor Type & Reference \\
\hline $\begin{array}{l}\text { Acetone, acetonitrile, 1-butanol, chloroform, } \\
\text { dichloromethane, ethanol, ethyl acetate, methanol, } \\
\text { 2-propanol, tetrahydrofuran, and toluene. }\end{array}$ & Single sensor & Liang et al., 2002 [37] \\
\hline $\begin{array}{l}\text { Acetonitrile, cyclohexane, isooctane, methanol, } \\
\text { tetrahydrofuran, and toluene. }\end{array}$ & Single sensor & Goubaidoulline et al., 2005 [73] \\
\hline Methanol, ethanol, n-propanol, and n-butanol. & Multi-sensor array & Seyama et al., $2006[74]$ \\
\hline Benzene, dichloromethane, ethanol, and heptane. & Multi-sensor array & Jin et al., 2006 [75] \\
\hline Methane & Single sensor & Jin et al., 2008 [84] \\
\hline $\begin{array}{l}\text { Acetone, benzene, dichloromethane, ethanol, methanol, } \\
\text { propanol, and toluene. }\end{array}$ & Single sensor & Xu et al., 2008 [78] \\
\hline Acetone, dichloromethane, ethanol, and toluene. & Multi-sensor array & Xu et al., 2009 [79] \\
\hline Dichloromethane, ethanol, hexane, and water. & Multichannel monolithic sensor array & Jin et al., 2009 [77] \\
\hline $\begin{array}{c}\text { Acetone, benzene, cyclohexane, ethanol, hexane, pyridine, } \\
\text { and toluene. }\end{array}$ & Single sensor & Ji et al., 2010 [86] \\
\hline Benzene, formaldehyde, methane, and natural gas. & Multi-sensor array & Hou et al., 2011 [85] \\
\hline $\begin{array}{l}\text { Acetic acid, acetone, butylamine, butylformate, butyric acid, } \\
\text { p-cresol, p-cymene, ethanol, ethylacetate, ethylbutanoate, } \\
\text { eugenol, hexane, hexanal, guaiacol, limonene, linalool, } \\
\text { menthol, methanol, methylacetate, 3-methyl-2-butanone, } \\
\text { methyl-isopropylketone, i-octane, octylamine, pentanal, } \\
\text { phenol, propanal, 1-propanol, 2-propanol, propionic acid, } \\
\text { propylamine, and } \alpha \text {-terpineol; headspace from Cinnamon } \\
\text { zeylanicum and Cinnamon cassia. }\end{array}$ & Multi-sensor array & Toniolo et al., 2013 [80] \\
\hline $\begin{array}{l}\text { Benzaldehyde, 2-butanone, butyraldehyde, formaldehyde, } \\
\text { formic acid, propionaldehyde, and propylamine }\end{array}$ & Single sensor & Tseng and Chu 2010 [87] \\
\hline $\begin{array}{l}\text { Acetone, 2-butanone, cycloheptanone, cylohexanone, } \\
\text { cyclopentanone, 3-pentanone, and propionaldehyde. }\end{array}$ & Single sensor & Liu et al., 2013 [89] \\
\hline $\begin{array}{l}\text { Allyl azide, benzyl azide, butyl azide, pentyl azide, phenyl } \\
\text { azide, and propyl azide. }\end{array}$ & Single sensor & Tseng and Chu 2014 [88] \\
\hline $\begin{array}{l}\text { Acetone, acetophenone, acrolein, benzaldehyde, } \\
\text { butyraldehyde, crotonaldehyde, cyclohexanone, } \\
\text { 2-cyclohexen-1-one, cyclopentanone, p-fluorobenzaldehyde, } \\
\text { formaldehyde, isobutyraldehyde, 3-methylcrotonaldehyde, } \\
\text { pivalaldehyde, p-tolualdehyde, and valeraldehyde. }\end{array}$ & Single sensor & Li et al., 2015 [91] \\
\hline
\end{tabular}


Table A1. Cont.

\begin{tabular}{|c|c|c|}
\hline VOCs or Complex Mixtures Analyzed & QCM Sensor Type & Reference \\
\hline $\begin{array}{l}\text { Acrolein, acryloyl chloride, cyclopentadiene, cyclopentene, } \\
\text { methyl acrylate, 1-pentene, and propylamine. }\end{array}$ & Single sensor & Hsu et al., 2016 [92] \\
\hline $\begin{array}{l}\text { Dimethylamine, ethanol, ethylamine, ethylmethylamine, } \\
\text { isoamylamine, isobutylamine, isopropylamine, } \\
\text { 2-methoxyethylamine, and propylamine. }\end{array}$ & Single sensor & Li and Chu 2020 [93] \\
\hline $\begin{array}{l}\text { Acetone, acetonitrile, 1-butanol, chloroform, ethanol, } \\
\text { methanol, 3-methyl-1-butanol, nitromethane, 1-propanol, } \\
\text { 2-propanol, and toluene. }\end{array}$ & Single sensor & Regmi et al., 2015 [107] \\
\hline $\begin{array}{l}\text { Benzene, chloroform, dichloromethane, ethanol, hexane, } \\
\text { heptane, methanol, 1-propanol, toluene, and xylenes. }\end{array}$ & Multi-sensor array & Vaughan et al., 2018 [108] \\
\hline $\begin{array}{l}\text { Acetone, acetonitrile, chloroform, ethanol, methanol, } \\
\text { 1-propanol, tetrachloromethane, and toluene. }\end{array}$ & Virtual sensor array & Regmi et al., 2012 [99] \\
\hline $\begin{array}{l}\text { Acetone, acetonitrile, chloroform, dichloromethane, ethanol, } \\
\text { ethyl acetate, methanol, nitromethane, 2-propanol, toluene, } \\
\text { and p-xylene. }\end{array}$ & Virtual sensor array & Regmi et al., 2014 [100] \\
\hline $\begin{array}{l}\text { Methanol, ethanol, 1-propanol, 1-butanol, 1-pentanol, } \\
\text { 1-hexanol, 1-octanol, dichloromethane, chloroform, } \\
\text { tetrachloromethane, 1,2-dichloroethane, 1-chlorohexane, } \\
\text { toluene, p-xylene, cyclohexane, n-hexane, acetonitrile, and } \\
\text { acrylonitrile; petroleum ether and kerosene. }\end{array}$ & Virtual sensor array & Speller et al., 2015 [98] \\
\hline $\begin{array}{l}\text { Lemon, lemon eucalyptus, lemongrass, lime, and orange } \\
\text { essential oils. }\end{array}$ & Virtual multi-sensor array & Speller et al., 2016 [102] \\
\hline $\begin{array}{l}\text { Methanol, ethanol, 1-propanol, 2-propanol, 1-butanol, } \\
\text { 2-butanol, 3-methyl-1-butanol, and 1-hexanol. }\end{array}$ & Virtual sensor array & Speller et al., 2017 [101] \\
\hline $\begin{array}{l}\text { Diesel, gasoline, kerosene, and petroleum ether; three } \\
\text { gasoline grades including Exxon plus, Exxon regular, and } \\
\text { Exxon supreme; samples of gasoline adulterated with } \\
\text { methanol, ethanol, toluene, and xylene. }\end{array}$ & Virtual multi-sensor array & Speller et al., 2017 [103] \\
\hline $\begin{array}{c}\text { Dichloromethane, chloroform, chloropropane, chlorobutane, } \\
\text { and tetrachloromethane. }\end{array}$ & Multi-sensor array and virtual sensor array & Vaughan 2020 [104] \\
\hline
\end{tabular}

\section{References}

1. U.S. Environmental Protection Agency. Technical Overview of Volatile Organic Compound. 2017. Available online: https: / / www.epa.gov/indoor-air-quality-iaq/technical-overview-volatile-organic-compounds (accessed on 29 June 2021).

2. Helen, G.S.; Jacob, P.; Peng, M.; Dempsey, D.A.; Hammond, S.K.; Benowitz, N.L. Intake of toxic and carcinogenic volatile organic compounds from secondhand smoke in motor vehicles. Cancer Epidemiol. Prev. Biomark. 2014, 23, 2774-2782. [CrossRef]

3. Schlosser, P.M.; Bale, A.S.; Gibbons, C.F.; Wilkins, A.; Cooper, G.S. Human health effects of dichloromethane: Key findings and scientific issues. Environ. Health Perspect. 2015, 123, 114-119. [CrossRef] [PubMed]

4. Ohura, T.; Amagai, T.; Shen, X.; Li, S.; Zhang, P.; Zhu, L. Comparative study on indoor air quality in Japan and China: Characteristics of residential indoor and outdoor VOCs. Atmos. Environ. 2009, 43, 6352-6359. [CrossRef]

5. Thazin, Y.; Eamsa-Ard, T.; Pobkrut, T.; Kerdcharoen, T. Formalin Adulteration Detection in Food Using E-Nose Based on Nanocomposite Gas Sensors; IEEE: Piscataway, NJ, USA, 2019; pp. 64-67.

6. Agarwal, S.; Prajapati, Y.K.; Mishra, V. Thinned fibre Bragg grating as a fuel adulteration sensor: Simulation and experimental study. Opto Electron. Rev. 2015, 23, 231-238. [CrossRef]

7. Torres-Tello, J.; Guaman, A.V.; Ko, S.-B. Improving the Detection of Explosives in a MOX Chemical Sensors Array with LSTM Networks. IEEE Sens. J. 2020, 20, 14302-14309. [CrossRef]

8. Palma, S.I.C.J.; Traguedo, A.P.; Porteira, A.R.; Frias, M.J.; Gamboa, H.; Roque, A.C.A. Machine learning for the meta-analyses of microbial pathogens' volatile signatures. Sci. Rep. 2018, 8, 1-15. [CrossRef] [PubMed]

9. Li, Z.; Paul, R.; Tis, T.B.; Saville, A.C.; Hansel, J.C.; Yu, T.; Ristaino, J.B.; Wei, Q. Non-invasive plant disease diagnostics enabled by smartphone-based fingerprinting of leaf volatiles. Nat. Plants 2019, 5, 856-866. [CrossRef] [PubMed]

10. Nakhleh, M.K.; Broza, Y.Y.; Haick, H. Monolayer-capped gold nanoparticles for disease detection from breath. Nanomedicine 2014, 9, 1991-2002. [CrossRef]

11. Nakhleh, M.K.; Amal, H.; Jeries, R.; Broza, Y.Y.; Aboud, M.; Gharra, A.; Ivgi, H.; Khatib, S.; Badarneh, S.; Har-Shai, L. Diagnosis and classification of 17 diseases from 1404 subjects via pattern analysis of exhaled molecules. ACS Nano 2017, 11, 112-125. [CrossRef] [PubMed]

12. Gardner, J.W.; Bartlett, P.N. A brief history of electronic noses. Sens. Actuators B Chem. 1994, 18, 210-211. [CrossRef] 
13. Martın, Y.G.; Oliveros, M.C.C.; Pavón, J.L.P.; Pinto, C.G.; Cordero, B.M. Electronic nose based on metal oxide semiconductor sensors and pattern recognition techniques: Characterisation of vegetable oils. Anal. Chim. Acta 2001, 449, 69-80. [CrossRef]

14. Tan, J.; Xu, J. Applications of electronic nose (e-nose) and electronic tongue (e-tongue) in food quality-related properties determination: A review. Artif. Intell. Agric. 2020. [CrossRef]

15. Julian, T.; Hidayat, S.N.; Rianjanu, A.; Dharmawan, A.B.; Wasisto, H.S.; Triyana, K. Intelligent Mobile Electronic Nose System Comprising a Hybrid Polymer-Functionalized Quartz Crystal Microbalance Sensor Array. ACS Omega 2020, 5, $29492-29503$. [CrossRef]

16. Fan, X.; Du, B. Selective detection of trace p-xylene by polymer-coated QCM sensors. Sens. Actuators B Chem. 2012, 166, 753-760. [CrossRef]

17. Khot, L.R.; Panigrahi, S.; Lin, D. Development and evaluation of piezoelectric-polymer thin film sensors for low concentration detection of volatile organic compounds related to food safety applications. Sens. Actuators B Chem. 2011, 153, 1-10. [CrossRef]

18. Matsuguchi, M.; Uno, T. Molecular imprinting strategy for solvent molecules and its application for QCM-based VOC vapor sensing. Sens. Actuators B Chem. 2006, 113, 94-99. [CrossRef]

19. Jha, S.K.; Liu, C.; Hayashi, K. Molecular imprinted polyacrylic acids based QCM sensor array for recognition of organic acids in body odor. Sens. Actuators B Chem. 2014, 204, 74-87. [CrossRef]

20. Xu, F.; Sun, L.; Huang, P.; Sun, Y.; Zheng, Q.; Zou, Y.; Chu, H.; Yan, E.; Zhang, H.; Wang, J. A pyridine vapor sensor based on metal-organic framework-modified quartz crystal microbalance. Sens. Actuators B Chem. 2018, 254, 872-877. [CrossRef]

21. Ma, Z.; Yuan, T.; Fan, Y.; Wang, L.; Duan, Z.; Du, W.; Zhang, D.; Xu, J. A benzene vapor sensor based on a metal-organic framework-modified quartz crystal microbalance. Sens. Actuators B Chem. 2020, 311, 127365. [CrossRef]

22. Penza, M.; Cassano, G.; Aversa, P.; Cusano, A.; Cutolo, A.; Giordano, M.; Nicolais, L. Carbon nanotube acoustic and optical sensors for volatile organic compound detection. Nanotechnology 2005, 16, 2536. [CrossRef]

23. Consales, M.; Cutolo, A.; Penza, M.; Aversa, P.; Cassano, G.; Giordano, M.; Cusano, A. Carbon nanotubes coated acoustic and optical VOCs sensors: Towards the tailoring of the sensing performances. IEEE Trans. Nanotechnol. 2007, 6, 601-612. [CrossRef]

24. Schlupp, M.; Weil, T.; Berresheim, A.J.; Wiesler, U.M.; Bargon, J.; Müllen, K. Polyphenylene dendrimers as sensitive and selective sensor layers. Angew. Chem. Int. Ed. 2001, 40, 4011-4015. [CrossRef]

25. Lubczyk, D.; Siering, C.; Lörgen, J.; Shifrina, Z.B.; Müllen, K.; Waldvogel, S.R. Simple and sensitive online detection of triacetone triperoxide explosive. Sens. Actuators B Chem. 2010, 143, 561-566. [CrossRef]

26. Brunink, J.A.J.; Di Natale, C.; Bungaro, F.; Davide, F.A.M.; D'Amico, A.; Paolesse, R.; Boschi, T.; Faccio, M.; Ferri, G. The application of metalloporphyrins as coating material for quartz microbalance-based chemical sensors. Anal. Chim. Acta 1996, 325, 53-64. [CrossRef]

27. Paolesse, R.; Tortora, L.; Monti, D.; Nardis, S.; Stefanelli, M.; D'Amico, A.; Di Natale, C. Dip and wait: A facile route to nanostructured porphyrin films for QCM functionalization. Procedia Chem. 2009, 1, 180-183. [CrossRef]

28. Selyanchyn, R.; Korposh, S.; Wakamatsu, S.; Lee, S.-W. Respiratory monitoring by porphyrin modified quartz crystal microbalance sensors. Sensors 2011, 11, 1177-1191. [CrossRef]

29. Kumar, A.; Brunet, J.; Varenne, C.; Ndiaye, A.; Pauly, A.; Penza, M.; Alvisi, M. Tetra-tert-butyl copper phthalocyanine-based QCM sensor for toluene detection in air at room temperature. Sens. Actuators B Chem. 2015, 210, 398-407. [CrossRef]

30. Harbeck, M.; Erbahar, D.D.; Gürol, I.; Musluoğlu, E.; Ahsen, V.; Öztürk, Z.Z. Phthalocyanines as sensitive coatings for QCM sensors: Comparison of gas and liquid sensing properties. Sens. Actuators B Chem. 2011, 155, 298-303. [CrossRef]

31. Harbeck, S.; Göçmen, S.; Emirik, Ö.; Öztürk, Z.Z.; Ahsen, V.; Gürek, A.G. Synthesis of branched alkoxy side chains containing phthalocyanine derivates and their application in mass sensitive QCM sensors. Sens. Actuators B Chem. 2016, $233,55-62$. [CrossRef]

32. Temel, F.; Tabakci, M. Calix [4] arene coated QCM sensors for detection of VOC emissions: Methylene chloride sensing studies. Talanta 2016, 153, 221-227. [CrossRef]

33. Holloway, A.F.; Nabok, A.; Hashim, A.; Penders, J. The use of calixarene thin films in the sensor array for VOCs detection and olfactory navigation. Sens. Transducers 2010, 113, 71-81.

34. Ishii, R.; Naganawa, R.; Nishioka, M.; Hanaoka, T.-A. Microporous organic-inorganic nanocomposites as the receptor in the QCM sensing of toluene vapors. Anal. Sci. 2013, 29, 283-289. [CrossRef] [PubMed]

35. Van Quy, N.; Hung, T.M.; Thong, T.Q.; Huy, T.Q.; Hoa, N.D. Novel synthesis of highly ordered mesoporous $\mathrm{Fe}_{2} \mathrm{O}_{3} / \mathrm{SiO}_{2}$ nanocomposites for a room temperature VOC sensor. Curr. Appl. Phys. 2013, 13, 1581-1588. [CrossRef]

36. Zhang, K.; Hu, R.; Fan, G.; Li, G. Graphene oxide/chitosan nanocomposite coated quartz crystal microbalance sensor for detection of amine vapors. Sens. Actuators B Chem. 2017, 243, 721-730. [CrossRef]

37. Liang, C.; Yuan, C.-Y.; Warmack, R.J.; Barnes, C.E.; Dai, S. Ionic liquids: A new class of sensing materials for detection of organic vapors based on the use of a quartz crystal microbalance. Anal. Chem. 2002, 74, 2172-2176. [CrossRef]

38. Yu, L.; Garcia, D.; Ren, R.; Zeng, X. Ionic liquid high temperature gas sensors. Chem. Commun. 2005, 17, 2277-2279. [CrossRef]

39. Fauzi, F.; Rianjanu, A.; Santoso, I.; Triyana, K. Gas and humidity sensing with quartz crystal microbalance (QCM) coated with graphene-based materials-A mini review. Sens. Actuators A Phys. 2021, 330, 112837. [CrossRef]

40. Pérez, R.L.; Ayala, C.E.; Park, J.-Y.; Choi, J.-W.; Warner, I.M. Coating-Based Quartz Crystal Microbalance Detection Methods of Environmentally Relevant Volatile Organic Compounds. Chemosensors 2021, 9, 153. [CrossRef]

41. Wang, L. Metal-organic frameworks for QCM-based gas sensors: A review. Sens. Actuators A Phys. 2020, 307, 111984. [CrossRef] 
42. Hekiem, N.L.L.; Ralib, A.A.M.; Ahmad, F.; Nordin, A.N.; Ab Rahim, R.; Za'bah, N.F. Advanced vapour sensing materials: Existing and latent to acoustic wave sensors for VOCs detection as the potential exhaled breath biomarkers for lung cancer. Sens. Actuators A Phys. 2021, 329, 112792. [CrossRef]

43. Torad, N.L.; Zhang, S.; Amer, W.A.; Ayad, M.M.; Kim, M.; Kim, J.; Ding, B.; Zhang, X.; Kimura, T.; Yamauchi, Y. Advanced nanoporous material-based QCM devices: A new horizon of interfacial mass sensing technology. Adv. Mater. Interfaces 2019, 6, 1900849. [CrossRef]

44. Regmi, B.P. GUMBOS-and Ionic Liquid-Coated Quartz Crystal Microbalance Sensors for Detection and Molecular Weight Determination of Organic Vapors. Ph.D. Dissertation, Louisiana State University, Baton Rouge, LA, USA, 2014.

45. Lin, Z.; Ward, M.D. The role of longitudinal waves in quartz crystal microbalance applications in liquids. Anal. Chem. 1995, 67, 685-693. [CrossRef]

46. Muralidharan, V.S. Critical review on electrochemical quartz crystal micro balance-principles and applications to corrosion research. Bull. Electrochem. 2001, 17, 183-192.

47. Ogi, H. Wireless-electrodeless quartz-crystal-microbalance biosensors for studying interactions among biomolecules: A review. Proc. Jpn. Acad. Ser. B 2013, 89, 401-417. [CrossRef] [PubMed]

48. Sauerbrey, G. The use of quarts oscillators for weighing thin layers and for microweighing. Z. Phys. 1959, 155, 206-222. [CrossRef]

49. Alassi, A.; Benammar, M.; Brett, D. Quartz crystal microbalance electronic interfacing systems: A review. Sensors 2017, 17, 2799. [CrossRef] [PubMed]

50. Kanazawa, K.K.; Gordon Ii, J.G. The oscillation frequency of a quartz resonator in contact with liquid. Anal. Chim. Acta 1985, 175, 99-105. [CrossRef]

51. Dixon, M.C. Quartz crystal microbalance with dissipation monitoring: Enabling real-time characterization of biological materials and their interactions. J. Biomol. Tech. JBT 2008, 19, 151.

52. Rodahl, M.; Höök, F.; Krozer, A.; Brzezinski, P.; Kasemo, B. Quartz crystal microbalance setup for frequency and Q-factor measurements in gaseous and liquid environments. Rev. Sci. Instrum. 1995, 66, 3924-3930. [CrossRef]

53. Bandey, H.L.; Martin, S.J.; Cernosek, R.W.; Hillman, A.R. Modeling the responses of thickness-shear mode resonators under various loading conditions. Anal. Chem. 1999, 71, 2205-2214. [CrossRef]

54. Voinova, M.V.; Jonson, M.; Kasemo, B. Internal and interfacial friction in the dynamics of soft/solid interfaces. arXiv 1999, arXiv:cond-mat/9906415.

55. Çınar, S.; Schulz, M.D.; Oyola-Reynoso, S.; Bwambok, D.K.; Gathiaka, S.M.; Thuo, M. Application of Ionic Liquids in Pot-in-Pot Reactions. Molecules 2016, 21, 272. [CrossRef]

56. Gallagher, S.; Kavanagh, A.; Zíołkowski, B.; Florea, L.; MacFarlane, D.R.; Fraser, K.; Diamond, D. Ionic liquid modulation of swelling and LCST behavior of N-isopropylacrylamide polymer gels. Phys. Chem. Chem. Phys. 2014, 16, 3610-3616. [CrossRef] [PubMed]

57. Sowmiah, S.; Srinivasadesikan, V.; Tseng, M.-C.; Chu, Y.-H. On the chemical stabilities of ionic liquids. Molecules 2009, 14, 3780-3813. [CrossRef] [PubMed]

58. Cao, Y.; Mu, T. Comprehensive investigation on the thermal stability of 66 ionic liquids by thermogravimetric analysis. Ind. Eng. Chem. Res. 2014, 53, 8651-8664. [CrossRef]

59. Freemantle, M. New frontiers for ionic liquids. Chem. Eng. News 2007, 85, 23-26. [CrossRef]

60. Plechkova, N.V.; Seddon, K.R. Applications of ionic liquids in the chemical industry. Chem. Soc. Rev. 2008, 37, 123-150. [CrossRef]

61. Hantao, L.W.; Najafi, A.; Zhang, C.; Augusto, F.; Anderson, J.L. Tuning the selectivity of ionic liquid stationary phases for enhanced separation of nonpolar analytes in kerosene using multidimensional gas chromatography. Anal. Chem. 2014, 86, 3717-3721. [CrossRef]

62. Gao, T.; Andino, J.M.; Alvarez-Idaboy, J.R. Computational and experimental study of the interactions between ionic liquids and volatile organic compounds. Phys. Chem. Chem. Phys. 2010, 12, 9830-9838. [CrossRef]

63. Anderson, J.L.; Armstrong, D.W. High-stability ionic liquids. A new class of stationary phases for gas chromatography. Anal. Chem. 2003, 75, 4851-4858. [CrossRef]

64. Poole, C.F.; Poole, S.K. Ionic liquid stationary phases for gas chromatography. J. Sep. Sci. 2011, 34, 888-900. [CrossRef]

65. Collin, W.R.; Bondy, A.; Paul, D.; Kurabayashi, K.; Zellers, E.T. $\mu$ GC $\times \mu$ GC: Comprehensive two-dimensional gas chromatographic separations with microfabricated components. Anal. Chem. 2015, 87, 1630-1637. [CrossRef]

66. Regmi, B.P.; Chan, R.; Agah, M. Ionic liquid functionalization of semi-packed columns for high-performance gas chromatographic separations. J. Chromatogr. A 2017, 1510, 66-72. [CrossRef] [PubMed]

67. Cagliero, C.; Bicchi, C. Ionic liquids as gas chromatographic stationary phases: How can they change food and natural product analyses? Anal. Bioanal. Chem. 2020, 412, 17-25. [CrossRef]

68. Wei, D.; Ivaska, A. Applications of ionic liquids in electrochemical sensors. Anal. Chim. Acta 2008, 607, 126-135. [CrossRef] [PubMed]

69. Armstrong, D.W.; Zhang, L.-K.; He, L.; Gross, M.L. Ionic liquids as matrixes for matrix-assisted laser desorption/ionization mass spectrometry. Anal. Chem. 2001, 73, 3679-3686. [CrossRef] [PubMed]

70. Qiu, J.; Wang, H.; Zhao, Y.; Guan, P.; Li, Z.; Zhang, H.; Gao, H.; Zhang, S.; Wang, J. Hierarchically porous covalent organic frameworks assembled in ionic liquids for highly effective catalysis of C-C coupling reactions. Green Chem. 2020, 22, $2605-2612$. [CrossRef] 
71. Skoronski, E.; Fernandes, M.; Malaret, F.J.; Hallett, J.P. Use of phosphonium ionic liquids for highly efficient extraction of phenolic compounds from water. Sep. Purif. Technol. 2020, 248, 117069. [CrossRef]

72. Singh, S.K.; Savoy, A.W. Ionic liquids synthesis and applications: An overview. J. Mol. Liq. 2020, 297, 112038. [CrossRef]

73. Goubaidoulline, I.; Vidrich, G.; Johannsmann, D. Organic vapor sensing with ionic liquids entrapped in alumina nanopores on quartz crystal resonators. Anal. Chem. 2005, 77, 615-619. [CrossRef]

74. Seyama, M.; Iwasaki, Y.; Tate, A.; Sugimoto, I. Room-temperature ionic-liquid-incorporated plasma-deposited thin films for discriminative alcohol-vapor sensing. Chem. Mater. 2006, 18, 2656-2662. [CrossRef]

75. Jin, X.; Yu, L.; Garcia, D.; Ren, R.X.; Zeng, X. Ionic liquid high-temperature gas sensor array. Anal. Chem. 2006, 78, 6980-6989. [CrossRef] [PubMed]

76. Rehman, A.; Hamilton, A.; Chung, A.; Baker, G.A.; Wang, Z.; Zeng, X. Differential solute gas response in ionic-liquid-based QCM arrays: Elucidating design factors responsible for discriminative explosive gas sensing. Anal. Chem. 2011, 83, 7823-7833. [CrossRef]

77. Jin, X.; Huang, Y.; Mason, A.; Zeng, X. Multichannel monolithic quartz crystal microbalance gas sensor array. Anal. Chem. 2009, 81, 595-603. [CrossRef] [PubMed]

78. Xu, X.; Li, C.; Pei, K.; Zhao, K.; Zhao, Z.K.; Li, H. Ionic liquids used as QCM coating materials for the detection of alcohols. Sens. Actuators B Chem. 2008, 134, 258-265. [CrossRef]

79. Xu, X.; Cang, H.; Li, C.; Zhao, Z.K.; Li, H. Quartz crystal microbalance sensor array for the detection of volatile organic compounds. Talanta 2009, 78, 711-716. [CrossRef] [PubMed]

80. Toniolo, R.; Pizzariello, A.; Dossi, N.; Lorenzon, S.; Abollino, O.; Bontempelli, G. Room temperature ionic liquids as useful overlayers for estimating food quality from their odor analysis by quartz crystal microbalance measurements. Anal. Chem. 2013, 85, 7241-7247. [CrossRef]

81. Kachoosangi, R.T.; Musameh, M.M.; Abu-Yousef, I.; Yousef, J.M.; Kanan, S.M.; Xiao, L.; Davies, S.G.; Russell, A.; Compton, R.G. Carbon nanotube-ionic liquid composite sensors and biosensors. Anal. Chem. 2009, 81, 435-442. [CrossRef]

82. Bara, J.E.; Camper, D.E.; Gin, D.L.; Noble, R.D. Room-temperature ionic liquids and composite materials: Platform technologies for $\mathrm{CO}_{2}$ capture. Acc. Chem. Res. 2010, 43, 152-159. [CrossRef]

83. Correia, D.M.; Fernandes, L.C.; Martins, P.M.; García-Astrain, C.; Costa, C.M.; Reguera, J.; Lanceros-Méndez, S. Ionic liquidpolymer composites: A new platform for multifunctional applications. Adv. Funct. Mater. 2020, 30, 1909736. [CrossRef]

84. Jin, X.; Yu, L.; Zeng, X. Enhancing the sensitivity of ionic liquid sensors for methane detection with polyaniline template. Sens. Actuators B Chem. 2008, 133, 526-532. [CrossRef]

85. Hou, K.-Y.; Rehman, A.; Zeng, X. Study of ionic liquid immobilization on polyvinyl ferrocene substrates for gas sensor arrays. Langmuir 2011, 27, 5136-5146. [CrossRef]

86. Ji, Q.; Honma, I.; Paek, S.M.; Akada, M.; Hill, J.P.; Vinu, A.; Ariga, K. Layer-by-layer films of graphene and ionic liquids for highly selective gas sensing. Angew. Chem. Int. Ed. 2010, 49, 9737-9739. [CrossRef] [PubMed]

87. Tseng, M.-C.; Chu, Y.-H. Chemoselective gas sensing ionic liquids. Chem. Commun. 2010, 46, 2983-2985. [CrossRef] [PubMed]

88. Tseng, M.-C.; Chu, Y.-H. Reaction-based azide gas sensing with tailored ionic liquids measured by quartz crystal microbalance. Anal. Chem. 2014, 86, 1949-1952. [CrossRef]

89. Liu, Y.-L.; Tseng, M.-C.; Chu, Y.-H. Sensing ionic liquids for chemoselective detection of acyclic and cyclic ketone gases. Chem. Commun. 2013, 49, 2560-2562. [CrossRef] [PubMed]

90. Chang, Y.-P.; Liu, W.-C.; Tseng, M.-C.; Chu, Y.-H. Ionic liquids tailored for reaction-based gas sensing on quartz crystal microbalance. Rev. Anal. Chem. 2015, 34, 77-86. [CrossRef]

91. Li, H.-Y.; Hsu, T.-H.; Chen, C.-Y.; Tseng, M.-C.; Chu, Y.-H. Exploring silver ionic liquids for reaction-based gas sensing on a quartz crystal microbalance. Analyst 2015, 140, 6245-6249. [CrossRef]

92. Hsu, T.-H.; Chiang, S.-J.; Chu, Y.-H. Quartz Crystal Microbalance Analysis of Diels-Alder Reactions of Alkene Gases to Functional Ionic Liquids on Chips. Anal. Chem. 2016, 88, 10837-10841. [CrossRef] [PubMed]

93. Li, H.-Y.; Chu, Y.-H. Reaction-Based Amine and Alcohol Gases Detection with Triazine Ionic Liquid Materials. Molecules 2020, 25, 104. [CrossRef]

94. Peveler, W.J.; Yazdani, M.; Rotello, V.M. Selectivity and specificity: Pros and cons in sensing. ACS Sens. 2016, 1, 1282-1285. [CrossRef]

95. Länge, K. Bulk and surface acoustic wave sensor arrays for multi-analyte detection: A review. Sensors 2019, 19, 5382. [CrossRef] [PubMed]

96. Potyrailo, R.A. Multivariable sensors for ubiquitous monitoring of gases in the era of internet of things and industrial internet. Chem. Rev. 2016, 116, 11877-11923. [CrossRef] [PubMed]

97. Potyrailo, R.A. Toward high value sensing: Monolayer-protected metal nanoparticles in multivariable gas and vapor sensors. Chem. Soc. Rev. 2017, 46, 5311-5346. [CrossRef] [PubMed]

98. Speller, N.C.; Siraj, N.; Regmi, B.P.; Marzoughi, H.; Neal, C.; Warner, I.M. Rational Design of QCM-D Virtual Sensor Arrays Based on Film Thickness, Viscoelasticity, and Harmonics for Vapor Discrimination. Anal. Chem. 2015, 87, 5156-5166. [CrossRef]

99. Regmi, B.P.; Monk, J.; El-Zahab, B.; Das, S.; Hung, F.R.; Hayes, D.J.; Warner, I.M. A novel composite film for detection and molecular weight determination of organic vapors. J. Mater. Chem. 2012, 22, 13732-13741. [CrossRef] 
100. Regmi, B.P.; Speller, N.C.; Anderson, M.J.; Brutus, J.O.; Merid, Y.; Das, S.; El-Zahab, B.; Hayes, D.J.; Murray, K.K.; Warner, I.M. Molecular weight sensing properties of ionic liquid-polymer composite films: Theory and experiment. J. Mater. Chem. C 2014, 2, 4867-4878. [CrossRef]

101. Speller, N.C.; Siraj, N.; McCarter, K.S.; Vaughan, S.; Warner, I.M. QCM virtual sensor array: Vapor identification and molecular weight approximation. Sens. Actuators B Chem. 2017, 246, 952-960. [CrossRef]

102. Speller, N.C.; Siraj, N.; Vaughan, S.; Speller, L.N.; Warner, I.M. Assessment of QCM array schemes for mixture identification: Citrus scented odors. RSC Adv. 2016, 6, 95378-95386. [CrossRef]

103. Speller, N.C.; Siraj, N.; Vaughan, S.; Speller, L.N.; Warner, I.M. QCM virtual multisensor array for fuel discrimination and detection of gasoline adulteration. Fuel 2017, 199, 38-46. [CrossRef]

104. Vaughan, S.R.; Pérez, R.L.; Chhotaray, P.; Warner, I.M. Quartz Crystal Microbalance Based Sensor Arrays for Detection and Discrimination of VOCs Using Phosphonium Ionic Liquid Composites. Sensors 2020, 20, 615. [CrossRef]

105. Seddon, K.R.; Stark, A.; Torres, M.-J. Influence of chloride, water, and organic solvents on the physical properties of ionic liquids. Pure Appl. Chem. 2000, 72, 2275-2287. [CrossRef]

106. Aleixandre, M.; Nakamoto, T. Study of Room Temperature Ionic Liquids as Gas Sensing Materials in Quartz Crystal Microbalances. Sens. Basel 2020, 20, 4026. [CrossRef]

107. Regmi, B.P.; Galpothdeniya, W.I.S.; Siraj, N.; Webb, M.H.; Speller, N.C.; Warner, I.M. Phthalocyanine-and porphyrin-based GUMBOS for rapid and sensitive detection of organic vapors. Sens. Actuators B Chem. 2015, 209, 172-179. [CrossRef]

108. Vaughan, S.R.; Speller, N.C.; Chhotaray, P.; McCarter, K.S.; Siraj, N.; Pérez, R.L.; Li, Y.; Warner, I.M. Class specific discrimination of volatile organic compounds using a quartz crystal microbalance based multisensor array. Talanta 2018, 188, 423-428. [CrossRef]

109. Zhang, Y.; Qiao, X.; Zhao, W.; Sun, J.; Tang, Q.; Du, Y.; Jia, H.; Ji, Q. Highly Sensitive Gas-Sensing Films for Volatile Organic Acids from Imidazolium-Based Poly (ionic liquid) s. J. Nanosci. Nanotechnol. 2020, 20, 3588-3597. [CrossRef]

110. Sipka, R.; Vlcek, J.; Otta, J.; Hruska, M.; Tomecek, D.; Fitl, P.; Vrnata, M. Polymer Ionic Liquids as Perspective Materials for Chemiresistors and QCM Sensors; IOP Publishing: Bristol, UK, 2020; p. 2145.

111. Çapan, I.; Tarımc1, Ç.; Capan, R. Fabrication of Langmuir-Blodgett thin films of porphyrins and investigation on their gas sensing properties. Sens. Actuators B Chem. 2010, 144, 126-130. [CrossRef] 